\title{
John B. Watson: Behaviorista Metodológico?
}

\author{
Bruno Angelo Strapasson \\ Kester Carrara \\ Universidade Estadual de São Paulo
}

\begin{abstract}
RESUMO
A atribuição de rótulos ou adjetivos a propostas teóricas é sempre uma tarefa difícil e, infelizmente, poucas vezes empreendida com o devido cuidado. Este artigo pretende avaliar a caracterização da obra de John B. Watson como o exemplar emblemático do movimento conhecido como behaviorismo metodológico. São expostas no texto quatro concepções de behaviorismo metodológico (a de Lashley, 1923, de Skinner, 1945, de Day, 1983 e a implícita em Lopes Jr., 1993) e é avaliado, a partir de trechos dos textos do próprio Watson, o compromisso deste com as caracterizações expostas. Defende-se aqui que na maioria das acepções, a expressão behaviorismo metodológico não pode ser aplicada à obra de Watson e, quando pode, é adequada apenas aos seus primeiros escritos e não implica problemas filosóficos tradicionalmente atribuídos a essa caracterização, a saber: problemas inerentes ao dualismo mente-corpo. Por fim, são indicadas algumas conseqüências dessa caracterização apressada.
\end{abstract}

Palavras-chave: behaviorismo metodológico; ontologia; epistemologia.

\begin{abstract}
John B. Watson, Methodological Behaviorist?

To attribute titles or qualities to theoretical proposals is always a difficult task, and unhappily, it is rarely done carefully. This article intends to evaluate the characterizations of John B. Watson's writings as an emblem of the methodological behaviorism movement. The paper presents four conceptions of methodological behaviorism and discusses Watson's commitment to these views, in the light of his own writings. The paper then suggests that often, the expression Methodological Behaviorism could not be applied to Watson's writings, and when it can, it is adequate only to his initial texts and without implying the philosophical problems traditionally attributed to this characterization: the inherent problems of body-mind dualism. As a conclusion, the paper indicates some consequences of this mischaracterization.
\end{abstract}

Keywords: Methodological Behaviorism; ontology; epistemology.

Atribuir rótulos e adjetivos a teorias psicológicas não é uma tarefa fácil. As diversas palavras utilizadas para identificar correntes teóricas e suas subdivisões implicam definições que nem sempre são muito claras. Ao atribuir classificações corremos os "riscos inerentes a qualquer sistema de tipologia... [Nesses], há sempre uma tendência a argumentar que, porque indivíduos são similares em um aspecto, eles também são similares em outros" (Skinner, 1953/1965, p. 424). Se aplicarmos essa ressalva à classificação de teorias, veremos que diversas incorreções têm sido cometidas na psicologia e poderemos perceber a limitada utilidade dos manuais que assim o fazem. Muitos rótulos desse tipo têm sido atribuídos ao behaviorismo (e.g. diz-se que o behaviorismo é reducionista, continuísta, mecanicista, positivista etc. (Carrara, 2005)). Dada a multiplicidade de proposições teórico-metodológicas que se congregam sob o título "behaviorismo" a adequação desse rótulo na sua caracterização requer uma análise minuciosa, que deve passar por ao menos três fases: (1) a identificação de a qual behaviorismo essa classificação se dirige (e.g. o behaviorismo lógico de Ryle, o behaviorismo radical de B. F. Skinner etc.); (2) quais as características que determinado rótulo compartilha com o tipo de behaviorismo ao qual ele foi vinculado e (3) em que extensão essas características o influenciam, 
ou são determinantes dessa variante de behaviorismo. Entretanto, poucos são os trabalhos que se preocupam com essa caracterização pormenorizada.

Este artigo pretende explicitar algumas das características indicadas como definidoras do behaviorismo metodológico (doravante $\mathrm{BM}$ ) enfocando especialmente os compromissos ontológicos possíveis nessa tradição de pensamento e avaliando a compatibilidade entre a proposta watsoniana e a caracterização do BM.

\section{Behaviorismo metodológico}

Historicamente, o primeiro a utilizar a expressão "behaviorismo metodológico" parece ter sido K. S. Lashley (1923). Na sua concepção, BM refere-se às teorias behavioristas que utilizam o seguinte pressuposto: "fatos da experiência consciente existem, mas não servem a nenhuma forma de tratamento científico" (p. 238). Nesse entendimento, o BM seria uma proposta dualista que elege o comportamento observável como objeto legítimo da ciência psicológica e relega a experiência consciente a mera especulação metafísica. O próprio Lashley reconhece que Watson afasta-se dessa proposição no decorrer de sua obra, mas muitos autores ainda se referem à obra de Watson como emblemática do BM (Bergmann, 1956; Chiesa, 1994; Dutra, 2004; Guimarães, 2003; Matos, 1997; Weber, 1992).

O problema da proposta do BM na psicologia é que ela deixa os seus proponentes em uma situação no mínimo embaraçosa: ao assumir que eventos mentais existem, mas não são passíveis de análise científica, o behaviorista metodológico deixa de fora aquilo que tradicionalmente foi considerado como o campo de estudo legítimo da psicologia - a "atividade mental". Obviamente, essa postura impossibilitaria a maior reivindicação do behaviorismo watsoniano: de que o behaviorismo seria capaz de explicar toda a atividade humana. Portanto, um exame do comprometimento da proposta de Watson com o BM merece considerável atenção e será empreendida nesse artigo.

\section{Compromissos ontológicos e epistemológicos}

A caracterização do BM tal como Lashley (1923) o propõe implica certos compromissos ontológicos e epistemológicos ${ }^{2}$. Ela implica compromissos ontológicos na medida em que assume a existência de dois estofos no mundo, um físico e um mental, e implica compromissos epistemológicos quando afirma que apenas os eventos físicos - o comportamento observável - podem ser acessados cientificamente. Uma vez que esses compromissos constituem grandes fontes de problemas no BM são eles que este artigo irá enfatizar na tentativa de avaliar a compatibilidade da proposta de Watson com a caracterização do BM.

Um modo de avaliar os compromissos ontológicos e epistemológicos de um autor em psicologia é identificar aproximações ou distanciamentos das suas propostas às seguintes afirmações:

1) Existe apenas um estofo para as coisas do mundo e esse estofo é físico; o mundo é composto apenas por objetos físicos.

2) Existe apenas um estofo para as coisas do mundo e esse estofo é mental; o mundo não passa das nossas idéias subjetivas sobre coisas que não têm realidade própria.

3) Existem dois ou mais estofos no mundo, ao menos um físico e um mental; o homem seria composto de corpo, que funciona a partir das leis da física, e da mente, que é responsável pela subjetividade de cada ser humano; esta última funciona a partir de leis próprias.

4) É possível conhecer as propriedades e/ou funcionamento dos eventos subjetivos através de técnicas da psicologia/ciência.

5) É, em tese, possível conhecer propriedades e/ou funcionamento dos eventos subjetivos, mas ainda não desenvolvemos técnicas adequadas para a investigação desses eventos.

6) Não é possível conhecer propriedades e/ou funcionamento dos eventos subjetivos através de técnicas da psicologia/ciência; a natureza dos eventos psicológicos não é passível de investigação científica.

Pode-se perceber que as três primeiras afirmações tratam de compromissos ontológicos com a existência ou não da mente enquanto entidade não física e as três últimas tratam de compromissos epistemológicos que dizem respeito à possibilidade de se gerar conhecimento sobre os eventos subjetivos ${ }^{3}$. A união de afirmações ontológicas e epistemológicas caracteriza o modo geral como as diversas teorias abordam a questão dos eventos não observáveis: a privacidade. Não nos cabe aqui explorar todas as combinações possíveis entre as afirmações, mas no que concerne a nossa proposta, avaliaremos como o BM é caracterizado por alguns autores - quanto a seus compromissos ontológicos e epistemológicos nos termos propostos ante- 
riormente - e em que medida Watson se coaduna com essas caracterizações.

Uma interpretação que se tornou comum na psicologia é atribuir a Watson compromissos ontológicos com a existência de dois estofos, um mental e um físico (Afirmação 3), mas utilizando o argumento segundo o qual apenas os eventos físicos são passíveis de ser estudados pelos métodos da ciência e, portanto, os eventos privados não seriam parte de seu objeto de estudo (Afirmação 6): “[Watson, enquanto] behaviorista metodológico clássico, não nega a existência da mente, mas nega-lhe status científico ao afirmar que não podemos estudá-la pela sua inacessibilidade" (Matos, 1997, p. 65). Se essa interpretação estiver correta, o behaviorismo de Watson poderá ser considerado um exemplar do $\mathrm{BM}$, caso contrário esse rótulo tem sido atribuído indevidamente a Watson.

A classificação do behaviorismo watsoniano como BM decorre, em grande medida, da vinculação de Watson ao positivismo lógico (Matos, 1997) e para avançar na discussão precisamos caracterizar essa proposta teórica que influenciou a psicologia científica.

\section{Watson e o positivismo lógico}

O positivismo lógico foi uma proposta naturalista de ciência que surgiu em oposição ao idealismo alemão e que foi representado principalmente pelo chamado Círculo de Viena. O Círculo de Viena era composto de um grupo de cientistas, matemáticos, lógicos e filósofos europeus que propunham uma filosofia empiricista de compreensão da ciência. Para os positivistas lógicos o conhecimento científico era qualitativamente diferente e superior a outros discursos e apenas a linguagem científica era adequada para o exame das coisas do mundo (Moore, 1981). No positivismo lógico, uma proposição válida poderia ser analítica (desenvolvida através da aplicação da lógica formal sobre observações públicas) ou empiricamente verificável. Caso contrário, qualquer proposição científica seria sem sentido (Smith, 1986, p. 3). Desse modo, o positivismo lógico expulsou do campo da ciência discussões metafísicas e optou por adotar a linguagem fisicalista como a linguagem universal da ciência ${ }^{4}$. Um outro aspecto que é importante no positivismo lógico é que, como é freqüente em propostas radicais, seus autores via de regra adotavam um tom agressivo em suas proposições, o que funcionava muitas vezes como recurso retórico no estabelecimento e adoção de suas propostas. Isso se expressa, por exemplo, na proposição de que com o advento do positivismo lógico a maioria das discussões filosóficas seriam descartadas por serem sem sentido, ou seja, por não se referirem a dados empíricos ou a interpretações baseadas logicamente nos dados empíricos (Smith, 1986, p. 4).

O positivismo lógico tem sua origem formal em 1929, mas a expressão "positivismo lógico" é cunhada apenas em 1931 (16 anos depois do manifesto behaviorista e um ano depois da publicação do último livro de Watson, respectivamente) num artigo de Feigl e Blumberg chamado "Logical Positivism, a New Movement in European Philosophy" (Smith, 1986, nota 7, p. 331-332). A despeito dessa discrepância temporal e geográfica ${ }^{5}$ no desenvolvimento das duas propostas, alguns paralelos podem ser feitos entre o behaviorismo de Watson e o positivismo lógico, ainda que um comprometimento estrito entre as duas propostas seja duvidoso ${ }^{6}$.

Watson parece concordar com a tese verificacionista do positivismo lógico quando ao debater com MacDougall num seminário, que em 1929 se tornou um livro intitulado "The Battle of Behaviorism", defende que apenas o comportamento observável seria o objeto legítimo da ciência:

O que ele [o behaviorista] colocou no lugar [da introspecção]? O Behaviorista pergunta: Por que não fazemos do que podemos observar o real campo da psicologia? Limitemo-nos às coisas que podemos observar e formulemos leis que dizem respeito apenas às coisas observadas. Agora, o que podemos observar? Podemos observar comportamento - o que o organismo faz ou fala. (Watson, 1929, p. 19)

As teses do positivismo lógico se aproximam da proposta de Watson também no que compete à relutância para com a discussão metafísica. Embora Watson tenha se graduado em filosofia, ele mesmo indica que o pensamento filosófico não se consolidou nele por muito tempo (Marx \& Hillix, 1976, p. 228). Watson reitera esse posicionamento, especialmente frente à metafísica, ao caracterizar a proposta behaviorista:

O behaviorista gostaria de fixar a premissa, sem discutir suas muitas implicações metafisicas... $O$ behaviorista... desvia seu olhar... da premissa metafisica e pede apenas para que lhe permitam fazer observações sobre o que seu sujeito está fazendo sob dadas condições de estimulação. No lado metafísico 
ele pede apenas para ser colocado no mesmo cesto dos outros cientistas naturais. (Watson, 1920, p. 9394)

Entretanto, Watson parece evitar a discussão metafísica - e talvez esse seja um de seus maiores erros, ao menos no que se refere à discussão desse artigo - por motivos diferentes daqueles dos positivistas lógicos. Estes discordavam da validade lógica das proposições metafísicas por não serem empíricas ou analíticas, aquele considerava que a discussão metafísica não contribui diretamente na compreensão do comportamento.

Cabe aqui indicar também uma curiosidade histórica que pode ser interpretada apressadamente na comparação do behaviorismo de Watson com o positivismo lógico. Segundo Smith (1986, p. 61-62), muitos positivistas lógicos citavam trabalhos de Watson como exemplo do uso do fisicalismo (entendido aqui como compromisso com a Afirmação 1) na descrição científica. Entretanto, a proposta de Watson nunca foi completa o suficiente para legitimar a tese do fisicalismo, pois ele nunca conseguiu descobrir leis capazes de relacionar os predicados psicológicos com a fisiologia. Assim, a referência dos positivistas lógicos a Watson acabou permanecendo mais como um recurso retórico propagandista, por parte dos próprios positivistas, que como embasamento de suas propostas (Smith, 1986, p. 61-62).

Desse modo pode-se perceber certas aproximações entre o behaviorismo de Watson com o positivismo lógico. Por outro lado, parece-nos imprudente criar uma identidade entre as duas proposições teóricas ${ }^{7}$.

Analisemos mais detidamente as propostas de Watson. O chamado que Watson faz para pesquisar o observável e fazer dele seu objeto de estudo surge no contexto do debate com o introspeccionismo $e$ não carrega necessariamente um compromisso ontológico com o dualismo: é possível, por exemplo, assumir que não existem eventos não-físicos e que todos os eventos físicos são observáveis em princípio (Afirmações 1 e 5). Se esse for o caso, Watson não se isenta de compromissos ontológicos como faz o positivismo lógico (aonde a discussão em termos de compromissos ontológicos ou metafísicos é desprovida de sentido); na verdade ele estaria aderindo a um monismo físicalista (Afirmação 1).

Essa questão é central para a classificação ou não de Watson como behaviorista metodológico e, portanto, será mais bem discutida nos tópicos seguintes.
Primeiro, tentaremos caracterizar, a partir dos textos originais do autor, quais são os compromissos epistemológicos de Watson com o acesso a eventos privados ou subjetivos e em seguida discutiremos quais as implicações desses argumentos epistemológicos para possíveis compromissos ontológicos desse autor.

\section{Compromissos epistemológicos e ontológicos de Watson}

A principal reivindicação metodológica (agora se referindo apenas ao método e não à tradição de pensamento chamado de behaviorismo metodológico) do behaviorismo de Watson é a restrição de sua pesquisa aos eventos observáveis da atividade humana. Como indicado anteriormente, a exigência de se manter restrito aos eventos observáveis surge em contraposição à introspecção como método predominante na psicologia da época e que não podia ser aceito sob critérios científicos justamente pela sua natureza subjetiva (Watson, 1913, 1914, 1925, 1929). No chamado "manifesto behaviorista", Watson defende uma psicologia objetiva como única possibilidade da psicologia se emancipar como ciência.

A psicologia, tal como o behaviorista a vê, é um ramo puramente objetivo e experimental da ciência natural. A sua finalidade teórica é a previsão e controle do comportamento. A introspecção não constitui parte essencial de seus métodos e o valor científico de seus dados não depende do fato de se prestarem a uma fácil interpretação em termos de consciência... A Psicologia terá que descartar qualquer referência à consciência... ela já não precisa iludir-se que seu objeto de observação são os estados mentais (Watson, 1913, p. 158, 163)

Watson, portanto, abandona a consciência como objeto de estudo e adota o comportamento pela vantagem de que este é observável e, portanto, passível de estudo científico. Neste sentido, o argumento metodológico (rejeição dos métodos introspeccionistas e adoção de métodos observacionais como única possibilidade de ciência) é preponderante na obra de Watson, uma vez que vem determinar qual é o seu objeto de estudo: o comportamento observável. Essa primazia do método - que na classificação aqui proposta é representada pelo compromisso epistemológico com a Afirmação 6 - sobre o objeto tem sido indicada como a característica definidora do behaviorismo watsoniano, contudo, a ela têm sido vinculadas implicações ontológicas que não são logicamente necessárias. Por exemplo, a afirmação de que Watson aceita a existência da 
mente, mas a coloca de fora do escopo da ciência, parece considerar que a mudança metodológica proposta por Watson necessariamente não é acompanhada de mudanças nos seus compromissos ontológicos em relação à psicologia introspeccionista: $\mathrm{O}$ behaviorismo de Watson rejeitaria os métodos usados pelos instrospeccionistas, mas não rejeitaria a existência do objeto de estudo deles, a consciência/mente. Entretanto, se estiver correta a afirmação de Lopes Jr. (1993) de que a viabilidade do behaviorismo enquanto teoria psicológica depende da capacidade de tal proposta "incluir em seu arcabouço empírico e conceitual, os eventos não observáveis publicamente" (p. 273), assumir que a proposta do behaviorismo de Watson se recusa a estudar os eventos subjetivos é o mesmo que assumir sua insuficiência enquanto teoria psicológica. E essa não parece ser a compreensão que Watson tem de seu behaviorismo (Watson, 1913, 1925, 1929).

Primeiramente, vejamos alguns elementos que podem justificar a classificação do behaviorismo de Watson como "Metodológico" para depois avaliar os argumentos em contrário a essa proposição. No artigo de 1913 (Watson, 1913) alguns elementos podem ser utilizados para vincular a proposta de Watson a um apelo estritamente epistemológico. Ao especular sobre um possível compromisso com o fisicalismo, Watson deixa brechas a essas interpretações:

Seria então deixado para a psicologia um mundo puramente físico, para usar o termo de Yerkes? Eu confesso que não sei. Os planos aos quais sou mais favorável para a psicologia levam praticamente a ignorar a consciencia no sentido em que o termo é utilizado pelos psicólogos hoje. Eu tenho virtualmente negado que esse campo da física é aberto à investigação experimental. Eu não quero ir além nesse problema no presente porque ele leva inevitavelmente para dentro da metafísica. (Watson, 1913, p. 175 , grifo acrescentado)

Apesar de o trecho acima atestar principalmente a indiferença de Watson para com a metafísica, ele é freqüentemente utilizado como indício de que ele assumiria a possibilidade da existência de um estofo não físico. Nesse caso, o desprezo de Watson para com os compromissos metafísicos é interpretado como se ele não se incomodasse em admitir um dualismo mente-corpo. Entretanto, é interessante notar que ao reproduzir parte desse texto numa outra obra (Watson, 1914) ele omite a expressão grifada. Talvez as críticas recebidas pela ocasião da publicação do artigo de 1913 tenham motivado Watson a assumir um compromisso mais estreito com um monismo fisicalista. Um argumento que apóia essa hipótese é o fato de que no artigo de 1913 há, além da expressão indicada anteriormente, um outro parágrafo que é omitido na reprodução desse texto no ano seguinte:

Certamente a posição que eu advogo é fraca o suficiente no presente e pode ser atacada por vários pontos de partida. Ainda quando tudo isso é admitido eu continuo a sentir que essa consideração a qual eu tenho incitado deve ter grande influência sobre o tipo de psicologia que será desenvolvida no futuro. (Watson, 1913, p. 175)

Esses trechos, em conjunto, parecem ser indicativos de que o próprio Watson, apesar de inicialmente considerar as questões metafísicas secundárias em relação à priorização do método, acreditava que elas inevitavelmente seriam discutidas durante o amadurecimento de sua proposta científica. E Watson não deixou essas questões sob responsabilidade apenas de seus possíveis seguidores, como ficará explicito a seguir.

Vejamos agora trechos da própria obra de Watson que indicam um afastamento do posicionamento dualista do BM. Watson questiona em vários momentos os compromissos ontológicos de seu behaviorismo (e.g., Watson, 1920, p. 94; 1925, p. 4, 6, 10; 1929, p. $23,35-36)$, ainda que seu interesse nesses momentos permanecesse mais voltado a responder aos introspeccionistas que debater metafísica.

Em 1920, por exemplo, ao responder a Thomson, que questionava seus compromissos ontológicos, Watson afirma:

O introspeccionista espera por uma solução do problema metafísico através de algum autoconhecimento místico. O behaviorista não acredita em nenhum poder humano transcendental como esse. Ele mesmo é apenas um sistema complexo de reação e deve ficar contente em desenvolver sua análise com as mesmas ferramentas que ele observa seu sujeito usando. Eu não posso, conseqüentemente, concordar com o Sr. Thompson que existe um problema mente-corpo no Behaviorismo. É uma séria falta de compreensão da posição behaviorista dizer, como o Sr. Thomson diz - "E é claro que o behaviorista não nega que estados mentais existem. Ele meramente prefere ignorá-los". Ele os 'ignora', no mesmo sentido que a química ignora a alquimia, a astronomia o horóscopo, e a psicologia a telepatia e manifestações psíquicas. O behaviorista não se interessa por eles porque, na medida em que a correnteza de sua 
ciência se amplia e aprofunda, esses antigos conceitos são sugados por ela, para nunca mais reaparecerem. (Watson, 1920, p. 94)

Em outra obra, ao discutir as possíveis limitações do seu behaviorismo, Watson antecipa seu interlocutor:

A psicologia do comportamento deixa algo de fora? Professor MacDougall irá, sem dúvida, dizer que o behaviorista seleciona seus problemas. Ele irá admitir que o tipo de trabalho que eu venho esboçando é valioso para a sociedade, mas ele irá dizer-lhe que existem muitas outras fases na psicologia que o behaviorista estudiosamente e possivelmente ignorantemente [ignorantly] rejeita. Um problema desse tipo é o "pensar". Como você pode explicar o "pensamento" em termos behavioristas? Fazer isso requer um tempo considerável.

O aumento da dominância de hábitos de linguagem no comportamento de uma criança em desenvolvimento leva naturalmente à concepção behaviorista do pensar. O behaviorista não vê mistérios no pensar. Ele defende que pensar é comportamento, é organização motora, tal como jogar golfe ou qualquer outra forma de atividade muscular. (Watson, 1929, p. 32-33)

Não nos cabe aqui explicar longamente a teoria dos hábitos de linguagem de Watson, mas no que compete a esse trabalho, é importante ressaltar que sua proposta prevê que toda ação humana é comportamento, mas parte desse comportamento ocorre em escala tão pequena que não conseguimos observar sem instrumentos (e.g. esse é o caso do pensar). Se, por um lado, Watson começou advogando que a psicologia deveria se restringir aos comportamentos observáveis, pois sobre esses é possível criar leis científicas, por outro lado, ao longo de sua obra, ele defendia que há comportamentos que são difíceis de observar, mas que, como também são eventos físicos ${ }^{8}$, com o desenvolvimento da tecnologia se tornariam observáveis, ou seja, eram observáveis em princípio (Lashley, 1923; Watson, 1920, 1925). Uma vez que a atividade humana era composta ou de comportamentos observáveis ou de comportamentos potencialmente observáveis, não havia mais espaço em sua teoria para eventos que acontecessem em um plano não físico, constatação essa que contraria afirmações como a de Guimarães: "Watson não negava a existência da mente ou de processos cognitivos, mas afastava-se deles, pois não havia como estudá-los, uma vez que são eventos inacessíveis a um segundo observador" (2003, p. 64).
Se a interpretação aqui proposta estiver correta, Watson assume um compromisso ontológico com o fisicalismo, evitando que a caracterização que Lashley (1923) faz de BM possa ser aplicada à sua teoria. Desse modo, sua proposta parece aproximar-se mais das afirmações 1 e 5 que das afirmações 3 e 6 . É interessante notar que historiadores que se dedicaram a explorar a obra de Watson ressaltam seu compromisso com um monismo fisicalista como uma das características mais importantes e radicais ${ }^{9}$ de sua proposta teórica (Bergman, 1952, p.269-270; Marx \& Hillix, 1976, p. 34-38; Shneider \& Morris, 1987, p. 34-35).

\section{O behaviorismo metodológico para Skinner}

Um outro autor contemporâneo importante na caracterização do BM foi B.F. Skinner. Em 1945 Skinner publicou um artigo chamado The Operational Analyisis of Psychological Terms (Skinner, 1945/1984) onde caracteriza pela primeira vez o que entende por behaviorismo metodológico. Para ele o $\mathrm{BM}$ seria uma doutrina segundo a qual "o mundo é dividido em eventos públicos e privados; e a psicologia, para atender os requisitos da ciência, deve se confinar ao primeiro. Essa nunca foi uma boa forma de behaviorismo, mas era uma posição fácil de expor e defender e que se tornou recorrente para os próprios behavioristas" (Skinner, 1945/1984, p. 552). As diferenças entre o BM e o behaviorismo radical, apesar de muitas, foram devidamente exploradas em outros trabalhos (e.g., Day, 1983; Leigland, 1997; Moore, 1981, 2001) e não serão desenvolvidas aqui. O que interessa a este artigo é que muitos dos que caracterizam Watson como behaviorista metodológico (Chiesa, 1994; Guimarães, 2003; Matos, 1997; Weber, 1992) denominam-se behavioristas radicais inspirados em Skinner. Como se pode perceber, para Skinner o BM é caracterizado principalmente pelo apelo metodológico de excluir os eventos privados da ciência psicológica, entretanto, o problema principal surge porque "a maioria dos behavioristas metodológicos mantiveram a existência de eventos mentais enquanto os excluíam de consideração" (Skinner, 1974, p. 13), assumindo assim um dualismo consistentemente combatido por Skinner. Contudo, em nenhum momento, nem mesmo num artigo em que Skinner comenta especificamente a obra de Watson (Skinner, 1959), este é classificado como behaviorista metodológico (cf. Skinner, 1945/ 1984, 1959, 1974). E, se concordarmos com a tese proposta anteriormente de que Watson defende um monismo fisicalista, ele não pode ser caracterizado como behaviorista metodológico segundo os critérios de Skinner. 


\section{A caracterização de behaviorismo metodológico de Willard Day}

Em 1977, Willard Day apresentou um trabalho chamado On the difference between Radical and Methodological Behaviorism que foi publicado na forma de artigo apenas em 1983, onde ele defendeu uma caracterização do BM centrada "[n]uma orientação profissional abrangente sobre como deve-se conduzir a pesquisa psicológica em geral" (p. 91) e que seria um erro "restringir a concepção de behaviorismo metodológico apenas ao comprometimento com uma base de dados publicamente observável" (p. 90). A caracterização de Day (1983) inclui, além da restrição aos eventos observáveis - principalmente através da aplicação do operacionismo na definição dos conceitos mentais - o raciocínio hipotético-dedutivo, uso do método experimental, uso da estatística na avaliação dos resultados, adesão a um modelo de causação antecedente e formulação de teorias explicativas dos dados obtidos, geralmente por meio de instâncias mediadoras inferidas. Essas características implicariam uma espécie de realismo ingênuo derivado, historicamente, do positivismo lógico e do operacionismo clássico na psicologia (i.e., operacionismo de BoringStevens) (Day, 1983).

Essa concepção de BM é compartilhada por alguns autores contemporâneos do behaviorismo, como Moore (1981, 2001) e Leigland (1997) e é freqüentemente indicada como "efeito da epistemologia mentalista na ciência do comportamento" (Moore, 1981, p. 64). O BM seria mentalista na medida em que apela para construtos hipotéticos na explicação do comportamento como objeto e na explicação do comportamento do cientista que o estuda (Moore, 1981, Day, 1983). Desse modo, "se alguém for um behaviorista metodológico, esse alguém usualmente será também um mentalista, mas alguém não precisa ser sempre assim. Exemplos de mentalismo que não envolvem necessariamente o behaviorismo metodológico são certos tipos de psicologia da Gestalt, a fenomenologia e a psicologia humanista" (Moore, 1981, p. 64). Nessa concepção de BM poderiam ser enquadrados os neobehavioristas mediacionais (e.g., Hull) e quase todo o abrangente campo da psicologia cognitiva, dentre outros (Leigland, 1997), contudo, dificilmente qualquer leitor atento de Watson o classificaria como um mentalista. Alguém poderia ainda classificar Watson como behaviorista metodológico por compartilhar algumas das características do BM tal como descrito por Day (1983), indicando, por exemplo, um comprometimento de Watson com a noção de causação antecedente. Entretanto, o fato de algumas teorias mentalistas (e.g. fenomenologia, etc.) não serem classificadas como BM pelos autores que propõem essa caracterização nos indica que compartilhar apenas algumas características não é suficiente para classificar uma proposta teórica como BM. Portanto, nem mesmo nessa definição mais moderna Watson poderia ser classificado como um behaviorista metodológico.

\section{O behaviorismo metodológico como priorização do método}

Watson é freqüentemente chamado de metodológico por priorizar o método em detrimento do objeto de estudo (Lopes Jr, 1993, p. 273). Neste sentido, Watson teria inicialmente feito um apelo metodológico: "limitemo-nos às coisas que podemos observar e formulemos leis que dizem respeito apenas às coisas observadas" (Watson, 1929, p. 19); para apenas a partir desse movimento definir o seu objeto de estudo: "agora, o que podemos observar? Podemos observar comportamento - o que o organismo faz ou fala" (p. 19). Esta priorização do método sobre o objeto seria determinante no rompimento de sua proposta com as psicologias desenvolvidas até a década de 1920 (Lopes Jr., 1993). Esta interpretação ganha algum suporte no chamado "manifesto behaviorista":

Eu estou mais interessado no presente momento em tentar mostrar a necessidade de manter uniformidade no procedimento experimental e no método de dispor os resultados no trabalho de ambos, animal e homem, que desenvolver quaisquer idéias que eu tenho sobre as mudanças que devem certamente acontecer no escopo da psicologia humana. (Watson, 1913 , p. 170)

Neste sentido, Watson seria um behaviorista metodológico apenas pela priorização de aspectos epistemológicos de sua proposta e não por algum alinhamento com propostas dualistas, como vimos anteriormente. Por outro lado, identificar que Watson teria desenvolvido argumentos epistemológicos (devemos fazer uma ciência do comportamento observável) antes de definir seus compromissos ontológicos (todo comportamento é físico e, portanto, observável em tese), não traz grandes implicações para o seu projeto científico, uma vez que não altera os compromissos ontológicos por ele assumidos. No máximo, o adjetivo metodológico, quando empregado com esse sentido, pode sugerir a identificação de duas fases no behaviorismo watsoniano (antes e depois de explicitar seus 
compromissos ontológicos), identificação essa que cabe aos historiadores interessados estabelecerem ou não.

\section{CONSIDERAÇÕES FINAIS}

Parece adequado, neste momento, resumir algumas considerações sobre o que foi exposto até agora. Muitos autores caracterizam o behaviorismo de Watson com o adjetivo "metodológico". Esse adjetivo, quando interpretado como um dualismo mente-corpo, é empregado erroneamente, e quando empregado indicando um percurso histórico - segundo o qual Watson expõe primeiro suas reivindicações epistemológicas e depois expõe os compromissos ontológicos - é irrelevante para a caracterização do conjunto de sua obra. Contudo, alguns trechos de seus escritos dão margem para as interpretações que acabamos de criticar. Sugere-se aqui que isso pode ser conseqüência da relutância de Watson em desenvolver abertamente os compromissos ontológicos de sua teoria. Para além da insuficiência do behaviorismo de Watson em explicar os comportamentos complexos, um outro fator que pode ter influenciado o seu abandono (e atual caracterização como BM) é sua insistência em desprezar a discussão metafísica em prol da formalização dos métodos que propôs. Para finalizar, gostaríamos de expor a forma como Lashley indica os compromissos ontológicos de Watson e seu afastamento da caracterização de behaviorismo metodológico que ele mesmo propôs:

A proposição do comportamento do organismo fisiológico não deixa nenhum resíduo psíquico. A mente é comportamento e nada mais. Essa visão está implícita em muitos dos escritos de Watson, ainda que não com tantas palavras. ...Essa é a visão behaviorista extrema. Ela não faz concessões à psicologia dualista e afirma a continuidade dos dados e métodos das ciências físicas, biológicas e psicológicas. (Lashley, 1923, p. 240)

Em se tratando dos compromissos ontológicos e epistemológicos tal como propusemos anteriormente, parece claro agora que Watson concordaria com as Afirmações 1 (existe apenas um estofo, o físico) e 5 (Todo o comportamento é observável em princípio, ainda que não exista tecnologia disponível para acessá-lo em toda sua complexidade), o que o coloca em uma posição bastante diferente das caracterizações de BM discutidas neste trabalho (usualmente representados pelas Afirmações 3 e 4 ou 3 e 6 dependendo da definição adotada).
Acreditamos que o descuido na classificação de teorias psicológicas é muito prejudicial à compreensão das próprias teorias e pode levar a graves incorreções na avaliação de propostas teóricas. Isso parece ser ainda mais prejudicial quando essas classificações carregam implicações filosóficas - no caso deste artigo, ontológicas e epistemológicas - as quais freqüentemente não estão claramente explícitas nos textos psicológicos.

Watson foi uma figura central na história da psicologia e seu nome é mencionado em qualquer tentativa de compreensão histórica dessa área do conhecimento. Nessa perspectiva, uma caracterização errônea de Watson como behaviorista metodológico pode deturpar a contribuição da historiografia na compreensão dos sistemas psicológicos. Watson foi o protagonista principal do chamado à objetividade na psicologia e classificações apressadas de sua obra obscurecem o cenário histórico polêmico incitado por suas proposições. Especificamente quanto ao behaviorismo, movimento do qual - ao menos historicamente Watson é apontado como fundador, as conseqüências da classificação de Watson como behaviorista metodológico são ainda mais danosas. O behaviorismo radical de Skinner, por exemplo, é freqüentemente caracterizado em contraposição ao BM (Bergmann, 1956; Chiesa, 1994; Day, 1983; Dutra, 2004; Grahan, 2007; Guimarães, 2003; Matos, 1997; Moore, 1981, 2001; Weber, 1992) e o uso da obra de Watson como exemplo emblemático do BM pode dificultar a compreensão, tanto do behaviorismo radical como do BM e da obra de Watson, impedindo, inclusive, a identificação adequada dos interlocutores de Skinner que influenciaram sua teoria. Com tantas conseqüências deletérias, uma classificação de Watson como behaviorista metodológico acaba se tornando apenas um recurso retórico com conotação pejorativa e deve ser evitado.

\section{REFERÊNCIAS}

Bergman, G. (1956). The contributions of John B. Watson. Psychological Review, 63, 265-276.

Carrara, K. (2005). Behaviorismo radical: Crítica e metacrítica. ( $2^{\mathrm{a}}$ ed.) São Paulo: Editora da UNESP.

Chiesa, M. (1994). Radical behaviorism: The philosophy and the science. Boston: Authors Cooperative.

Day, W. (1983). On the difference between radical and methodological behaviorism. Behaviorism, 11, 89-102.

Dutra, L. H. A. (2004). Behaviorismo, operacionismo e a ciência do comportamento. Philósophos, 9, 179-206. 
Guimarães, R. P. (2003). Deixando o preconceito de lado e entendendo o behaviorismo radical. Psicologia: Ciência e Profissão, 23, 60-67.

Lashley, K. S. (1923). The behaviorist interpretation of consciousness. Psychological Review, 30, 237-272.

Leigland, S. (1997). Systemns and theories in behavior analitic science: An overview of alternatives. Em L. J. Hayes, \& P. M. Ghezzi (Orgs.), Investigations in behavioral epistemology. (pp. 11-31) Reno: Context Press.

Lopes Jr., J. (1993). Aspectos históricos e espistemológicos da abordagem behaviorista: Sobre a transição entre o behaviorismo clássico e o neobehaviorismo. Psicologia: Teoria e Pesquisa, 9, 271-282.

Matos, M. A. (1997). O behaviorismo metodológico e suas relações com o behaviorismo radical. Em Sobre comportamento e cognição: Vol. 1. Aspectos teóricos metodológicos e de formação em análise do comportamento e terapia cognitiva (pp. 5769). Santo André: ESETec.

Marx, M. H., \& Hillix, W. A. (1976). Sistema e teorias em psicologia ( $3^{\mathrm{a}}$ ed.). (A. Cabral, Trad.). São Paulo: Cultrix.

Moore, J. (1981). On mentalism, methodological behaviorism, and radical behaviorism. Behaviorism, 9, 55-77.

Moore, J. (2001). On distinguishing methodological from radical behaviorism. European Journal of Behavior Analysis, 2, 221244.

Morris, E. K., \& Todd, J. T. (1999). Watsonian behaviorism. Em W. O'Donohue, \& R. Kitchener. (Orgs.), Handbook of Behaviorism (pp. 16-69). New York: Academic Press.

Shneider, S. M., \& Morris, E. K. (1987). A history of the term radical behaviorism: From Watson to Skinner. The Behavior Analyst, 10, 27-39.
Skinner, B. F. (1984). The operational analysis of psychological terms. Behavioral and Brain Sciences, 7, 547-572. (Original publicado em 1945)

Skinner, B. F. (1965). Science and human behavior. New York: Macmillan Publishing Co. (Original publicado em 1953)

Skinner, B. F. (1959). John Broadus Watson, behaviorist. Science, 129, 197-198.

Skinner, B. F. (1974). About behaviorism. New York: Knopf.

Smith, L. D. (1986). Behaviorism and logical positivism: A reassessment of the alliance. Stanford, CA: Stanford University Press.

Watson, J. B. (1913). Psychology as a behaviorist views it. Psychological Record, 20, 158-177.

Watson, J. B. (1914). Behavior: An introduction to comparative psychology. Philadelphia: Lippincott.

Watson, J. B. (1920). Is thinking merely the action of language mechanisms? British Journal of Psychology, 11, 87-104.

Watson, J. B. (1925). Behaviorism ( $2^{\mathrm{a}}$ ed.). London: Kegan Paul, Trench, Trubner \& Co.

Watson, J. B. (1929). Behaviorism: The modern note in psychology. Em J. B. Watson, \& W. McDougall, The battle of behaviorism: An exposition and an exposure (pp. 7-40). New York: Norton.

Weber, L. N. D. (1992, maio/agosto). Burrhus Frederic Skinner: Um homem além do seu tempo. Documenta CRP-08, 55-64.

Recebido: 21/09/2007

Última revisão: 05/01/2008 Aceite final: 20/02/2008

\section{Notas:}

${ }^{(*)}$ Os autores agradecem à FAPESP (bolsa de mestrado, proc. 06/53396-5) e ao CNPq (bolsa produtividade, proc. 304075/2005-1) pelo apoio recebido.

1 O’Donohue e Kitchener (1999) identificam pelo menos 15 subtipos de behaviorismo em seu Handbook of Behaviorism.

2 Para os fins desse trabalho entendemos como compromisso epistemológico as asserções sobre a possibilidade do conhecimento sobre um objeto de estudo - no caso sobre a mente - e entendemos como compromisso ontológico a adoção de axiomas sobre a existência real de um determinado objeto de estudo.

3 Utilizamos aqui o termo subjetivo fazendo referência "ao que é próprio do sujeito", desvinculando-o de qualquer compromisso ontológico: pode-se fazer questionamentos epistemológicos independente do estofo do qual é composta a subjetividade.

4 Ao adotar a linguagem fisicalista, o positivismo lógico não se compromete necessariamente com uma ontologia fisicalista, mesmo porque asserções sobre compromissos ontológicos não são analíticas (enunciados lógicos ou matemáticos baseados nos dados) nem empiricamente observáveis e portanto são asserções sem sentido. A adoção da linguagem fisicalista é, no positivismo lógico, apenas uma convenção. (e.g., Smith, 1986, p. 57-60)

5 O positivismo lógico foi um movimento iniciado na Europa e migrou para a América principalmente através da migração de intelectuais na $2^{\text {a }}$ Guerra Mundial (Smith, 1986, p. 6), de outro lado o behaviorismo foi um movimento tipicamente americano.

6 Justamente pela distância temporal entre o surgimento das duas propostas, seria impossível que o behaviorismo clássico de Watson fosse inspirado no positivismo lógico e a despeito das indicações de que os dois movimentos compartilharam influências de um contexto cultural e filosófico mais amplo, supor uma identidade entre os aspectos centrais das duas teorias seria uma supersimplificação, com efeitos nefastos para a compreensão de ambas as propostas. 
7 Aproximações maiores podem ser apontadas entre neobehavioristas como Hull e Spence (e.g., Smith, 1986).

8 Para Watson o pensamento, por exemplo, seria uma espécie de fala subvocal que poderia ser acessada com equipamentos que registrassem movimentos conspícuos da laringe, mas que não eram fortes o suficiente para emitir som (Watson, 1913, p. 174, nota, 1920, 1925, cap. X e XI, 1929a, p. 32, 1929b, cap. IX).

9 Marx e Hillix (1976) classificam o behaviorismo de Watson como "behaviorismo radical" dada a importância de seus apelos monistas em relação às teorias psicológicas vigentes na época do manifesto (i.e., estruturalismo e funcionalismo). Este é mais um exemplo de como classificações de teorias podem ser controversas, pois atualmente a expressão behaviorismo radical está mais vinculada ao behaviorismo de B. F. Skinner que de Watson. Neste caso, o termo "radical" surge por motivos bem diferentes dos de Watson mas essa diferença não será explorada aqui (cf. Shneider, \& Morris, 1987).

\section{Sobre os autores:}

Bruno Angelo Strapasson: Mestre em Psicologia do Desenvolvimento e Aprendizagem pela UNESP - Campus de Bauru. Endereço eletrônico: brunoastr@gmail.com.

Kester Carrara: Livre docente da UNESP - Campus de Bauru, professor do Programa de Pós-graduação em Psicologia do Desenvolvimento e Aprendizagem e Bolsista produtividade do CNPq. 